\title{
Frontalis Suspension Surgery in Upper Eyelid Blepharoptosis
}

\author{
Yasuhiro Takahashi ${ }^{1}$, Igal Leibovitch ${ }^{2}$ and Hirohiko Kakizaki ${ }^{*}, 1$ \\ ${ }^{I}$ Department of Ophthalmology, Aichi Medical University, Nagakute, Aichi 480-1195, Japan \\ ${ }^{2}$ Division of Oculoplastic and Orbital Surgery, Department of Ophthalmology, Tel-Aviv Medical Center, Tel-Aviv \\ University, Tel-Aviv, Israel
}

\begin{abstract}
Frontalis suspension is a commonly used surgery that is indicated in patients with blepharoptosis and poor levator muscle function. The surgery is based on connecting the tarsal plate to the eyebrow with various sling materials. Although fascia lata is most commonly used due to its long-lasting effect and low rate of complications, it has several limitations such as difficulty of harvesting, insufficient amounts in small children, and postoperative donor-site complications. Other sling materials have overcome these limitations, but on the other hand, have been reported to be associated with other complications. In this review we focus on the different techniques and materials which are used in frontalis suspension surgeries, as well as the advantage and disadvantage of these techniques.
\end{abstract}

Keywords: Frontalis suspension, suspensory material, surgical procedure, ptosis.

\section{INTRODUCTION}

Frontalis suspension is a commonly used surgery that is indicated in patients with blepharoptosis and poor levator muscle function. This surgery connects the eyelid to the brow with a sling material and utilizes the power of the frontalis muscle to elevate the poorly functioning eyelid.

Synthetic sutures were first used for frontalis suspension surgery more than 100 years ago [1]. In 1909, Payr was the first to introduce the use of autogenous fascia lata in congenital ptosis repair [2]. This technique was reintroduced by Wright in 1922 [3]. Because of its long-lasting effect and low rate of complications [4], fascia lata is considered the material of choice for frontalis suspension surgery. However, it has several limitations such as difficulty of harvesting, insufficient amounts in small children who are under 3 years of age, and postoperative donor-site complications [5].

Therefore, other sling materials were designed to overcome these limitations.

The aim of this article is to focus on the different techniques and materials which are used in frontalis suspension surgeries, as well as the advantage and disadvantage of these techniques.

\section{SURGICAL INDICATIONS}

Frontalis suspension surgery is indicated for blepharoptosis with poor levator muscle function. "Poor" function is defined as levator function of $4 \mathrm{~mm}$ or less, while levator function of 5-7 $\mathrm{mm}$ is considered "fair" and a function of $8 \mathrm{~mm}$ or more is considered "good" [6]. A large degree of levator muscle advancement during levator resection may result in reduced upper eyelid contact with the cornea, and endanger the cornea [7].

*Address correspondence to this author at the Department of Ophthalmology, Aichi Medical University, Nagakute, Aichi 480-1195, Japan; Tel: +81-56162-3311; Fax: +81-561-63-7255; E-mail: cosme@d1.dion.ne.jp
Blepharoptosis is classified into categories according to several parameters such as age at onset, etiology, severity, or levator muscle function. The main etiologic categories are myogenic, aponeurotic, neurogenic, mechanical, and traumatic [8] (Table 1).

Table 1. Etiologic Subclasses of Upper Eyelid Blepharoptosis

\begin{tabular}{|l|}
\hline Myogenic \\
simple congenital ptosis \\
double elevator palsy \\
blepharophimosis \\
congenital orbital fibrosis \\
mitochondrial myopathy \\
chronic progressive external ophthalmoplegia \\
Kearns-Sayre syndrome \\
mitochondrial myopathy, encephalopathy, lactic acidosis, stroke- \\
like episodes \\
mitochondrial encephalopathy with ragged red fibers \\
oculo-pharyngeal muscular dystrophy \\
facio-scapulo-humeral muscular dystrophy \\
myotonic dystrophy \\
\hline Aponeurotic \\
congenital defect in the aponeurosis \\
acquired aponeurotic ptosis \\
\hline Neurogenic \\
oculomotor palsy \\
Marcus-Gunn jaw winking syndrome \\
Horner's syndrome \\
myasthenia gravis \\
apraxia of lid opening \\
blepharospasm \\
\hline Traumatic \\
\hline
\end{tabular}


Frontalis suspension surgery is often used in blepharoptosis cases secondary to chronic progressive external ophthalmoplegia (CPEO), muscular dystrophy, third nerve palsy, myasthenia gravis, and aponeurotic ptosis in elderly patient, which are often associated with a poor Bell's phenomenon [8,9]. These cases require a carefully preoperative evaluated and surgical planning to prevent severe corneal damage secondary to postoperative lagophthalmos $[8,9]$.

\section{TIMING OF SURGICAL INTERVENTION}

In congenital ptosis cases, it is recommended that surgery be deferred until the patient is at least 3 to 5 years old, mainly to allow facial growth and maturation, as well as to ensure patients' cooperation during preoperative evaluation and measurements [8, 10-12]. In addition, in some older patients, surgery can be done under local anesthesia, which allows a better intraoperative quantification and therefore a better surgical outcome.

About $20-70 \%$ of patients with simple congenital ptosis will develop amblyopia [13-15], and it is more common in those with unilateral congenital ptosis [13]. One of the causes of amblyopia is astigmatism above 1.5 diopter [16], which can be induced by pressure from the upper eyelid on the cornea [14]. Other causes of amblyopia include visual axis deprivation, anisometropia, or convergence strabismus [13-15]. In such patients, early surgical repair of congenital ptosis is required to reduce the risk of amblyopia [17]. In addition to the visual aspects mentioned, the sleepy appearance in children with ptosis may have psychosocial aspects which warrant prompt surgical repair $[12,18]$.

In patients with a recent neurogenic or traumatic ptosis, it is advised to wait at least 6 to 12 months before a surgical intervention to allow spontaneous recovery or improvement of function [8].

\section{PREOPERATIVE EXAMINATION}

The general preoperative evaluation of patients planned to undergo frontalis suspension surgery is presented in Table 2.

A detailed history is the cornerstone of every preoperative evaluation [12]. Birth history may unveil traumatic factors during delivery, whereas family history may be helpful in identifying cases of blepharophimosis syndrome, orbital fibrosis syndrome, mitochondrial myopathies, muscular dystrophy, and thyroid eye disease. Patients with thyroid eye disease may develop pseudoptosis secondary to a contralateral upper eyelid retraction, and this could be further confirmed by thyroid function tests and imaging modalities. A history of diurnal fluctuation may point to myasthenia gravis as a possible cause of ptosis, which is then confirmed by analyzing serological antibodies and by the edrophonium (tensilon) test.

Eyelid height is a crucial measurement in preoperative evaluation of patients with ptosis [8]. The margin reflex distance-1 (MRD-1) is the distance from the upper eyelid margin to the light reflex on the cornea [12]. The normal

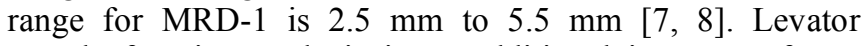
muscle function analysis is an additional important factor
Table 2. Preoperative Check-List before Frontalis Suspension Surgery for Upper Eyelid Blepharoptosis

\begin{tabular}{|l|}
\hline Questions of detailed history \\
birth history \\
family history \\
past history \\
history of diurnal fluctuation \\
\hline Ophthalmological examination \\
eyelid \\
levator function \\
Bell's phenomenon \\
Hering's law \\
lagophthalmos \\
eyelid crease position \\
eyelid lag \\
epicanthus and telecanthus \\
jaw-wink phenomenon \\
scar (previous trauma or surgery) \\
chin-up face position \\
brow elevation \\
pupillary examination \\
refraction and visual acuity \\
ocular motility and strabismus \\
tear secretion \\
slitlamp and funduscopic examination \\
\hline General examination \\
blood test \\
thinction receptor antibody \\
edomography or magnetic resonance image \\
\hline
\end{tabular}

which guides to the required surgical approach [8]. Measuring Bell's phenomenon, tear secretion and the degree of preoperative lagophthalmos is essential to predict any risk of postoperative corneal exposure [8,9].

A general ophthalmic examination, which is done before the operation, may unveil anisocoria in Horner's syndrome or third nerve palsy [12]. Ocular motility disturbances may be a sign of double elevator palsy, orbital fibrosis syndrome, CPEO, third nerve palsy, or thyroid eye disease [8]. Funduscopic evaluation in patients with CPEO may show a pigmentary retinopathy [8].

\section{SURGICAL APPROACHES}

There are many surgical approaches to pass the sling material (either autogenous or synthetic) from the eyelid to 
the brow area $[3,5,7,11,12,19-24]$. Most of the techniques are based on multiple cutaneous stab incisions at the level of the tarsus and the eyebrow, through which the sling material is passed in a sub-orbicularis plane.

There are various suture designs; a single triangle [11], double triangle [12], single rhomboid (Friedenwald-Guyton procedure) [19], double rhomboid (Iliff procedure) [20], double trapezoid (Wright procedure) [3], single pentagon (Fox procedure) [21], and double pentagon configurations (Crawford procedure) [5]. The single rhomboid loop is considered appropriate for young children, as it prevents postoperative bending of the eyelid [25]. Although the double loop suture is considered to allow separate adjustments of the medial and lateral upper eyelid heights, possibly resulting in an improved upper eyelid contour [26], a recent study have shown that the surgical outcomes of the single rhomboid loop and the double pentagonal sling were quite similar [27].

Postoperative sling slippage with early recurrence of ptosis may sometimes occur after ptosis repair, particularly when silicone or monofilament sutures are used [28-30]. A wide skin incision with anchoring of the sling material to the tarsus is effective in preventing this complication (Fig. 1) $[31,32]$. This procedure is also useful in creating an eyelid crease [22], which is usually absent in children with congenital ptosis. Lash ptosis is also often observed [8], mainly because the levator muscle is extremely weak and thus unable to pull the skin and eyelashes appropriately [33].

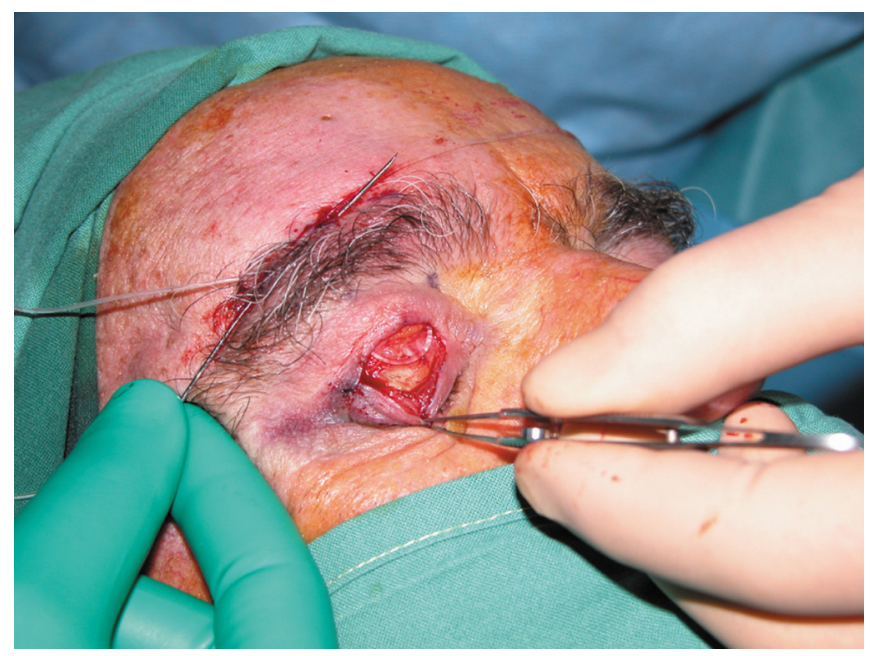

Fig. (1). Silicone rod sling with an eyelid crease skin incision.

A sheet-shaped material can be used in ptosis surgery (Fig. 2A) [7, 22-24]. We use the polytetrafluoroethylene $\left(\right.$ Gore-tex ${ }^{\circledR}$ ) sheet for its stability and postoperative adjustability. Initially, a wide skin incision (Fig. 2B) and stab incision above the eyebrow (Fig. 2C) are made. Next, a suborbicularis tunnel is created between the incisions. The sling material is fixed to the tarsus, after which the eyelid crease is created (Fig. 2D). The sling material is passed through the tunnel (Fig. 2E) and fixed at the subcutaneous tissue of the eyebrow (Fig. 2F). The advantage of this procedure is that it allows a broad fixation of the sling material to the tarsus, thereby creating a natural upper eyelid curvature and an appropriate eyelid elevation with long-term stability [7]. However, as this sling material may be conspicuous through the skin in patients with an upper eyelid sulcus (which is more typical in Caucasians), this procedure may be more suitable for Asian patients [7].

In some patients, additional procedures may be needed to achieve an adequate eyelid elevation. One example is the blepharophimosis syndrome, which is characterized by blepharophimosis, ptosis with poor levator function, and epicanthus inversus [12]. The preceding canthoplasty facilitates the suspension surgery $[8,11]$. Another example is the jaw-winking ptosis, characterized by ptosis during inactivity of the masticatory muscles [8]. Unilateral elevation of the upper eyelid during mastication is caused by an aberrant innervation from the fifth cranial nerve to the third cranial nerve [8]. Disinsertion of the levator muscle with subsequent frontalis suspension surgery is considered the procedure of choice [8].

\section{SUSPENSORY MATERIALS}

\section{Autogenous Graft Materials}

The most commonly used autogenous materials are fascia lata, the palmaris longus tendon [23], and the temporal fascia [22]. Most surgeons prefer fascia lata because it is more easily harvested than the other two materials; thereby we focus here mainly on this material.

\section{Autogenous Fascia Lata}

Sling surgery with autogenous fascia lata is still considered the gold standard procedure for congenital ptosis, having a long-lasting effect for upper eyelid elevation [8, 27, 34]. When a piece of free autogenous fascia is transplanted to the eyelid, it can easily survive [3]. Two recent comparative studies have shown that using a fascia lata sling is more effective than other materials, except for Gore-Tex ${ }^{B}$ (Table 3) [27, 34]. Another recent study has shown that the functional success rate with a fascia lata sling was high (94\%) at 18 months [24]. In addition, the fascia lata sling has a low rate of complications such as infections, extrusion, breakage and granuloma formation [34]. Crawford suggested that autogenous fascia lata should only be performed in patients over 3 years of age because inadequate amounts of material could be harvested in younger patients [5]. However, a more recent study has shown that fascia lata can also be used successfully in children under 3 years of age [35]. The main disadvantages of a surgical repair using autogenous fascia lata is the need for a second surgical site to harvest the fascia with the possible risks to the donor site [18], as well as the fact that fascia lata may cause cicatricial contracture of the upper eyelid, which cannot be easily repaired [7]. Histopathologic findings in such cases have shown that the scarring of the fascia was demonstrated long after surgery [36].

\section{Allogenic Materials \\ Banked Fascia Lata}

Banked (irradiated or lyophilized) allogenic fascia lata is an alternative sling material. Crawford first tried to use the preserved fascia lata for frontalis suspension surgery because of insufficient harvesting of the fascia lata in young patients $[4,5,37-40]$. The banked fascia may be replaced by fibrous tissue, which may provide a permanent effect. However, 


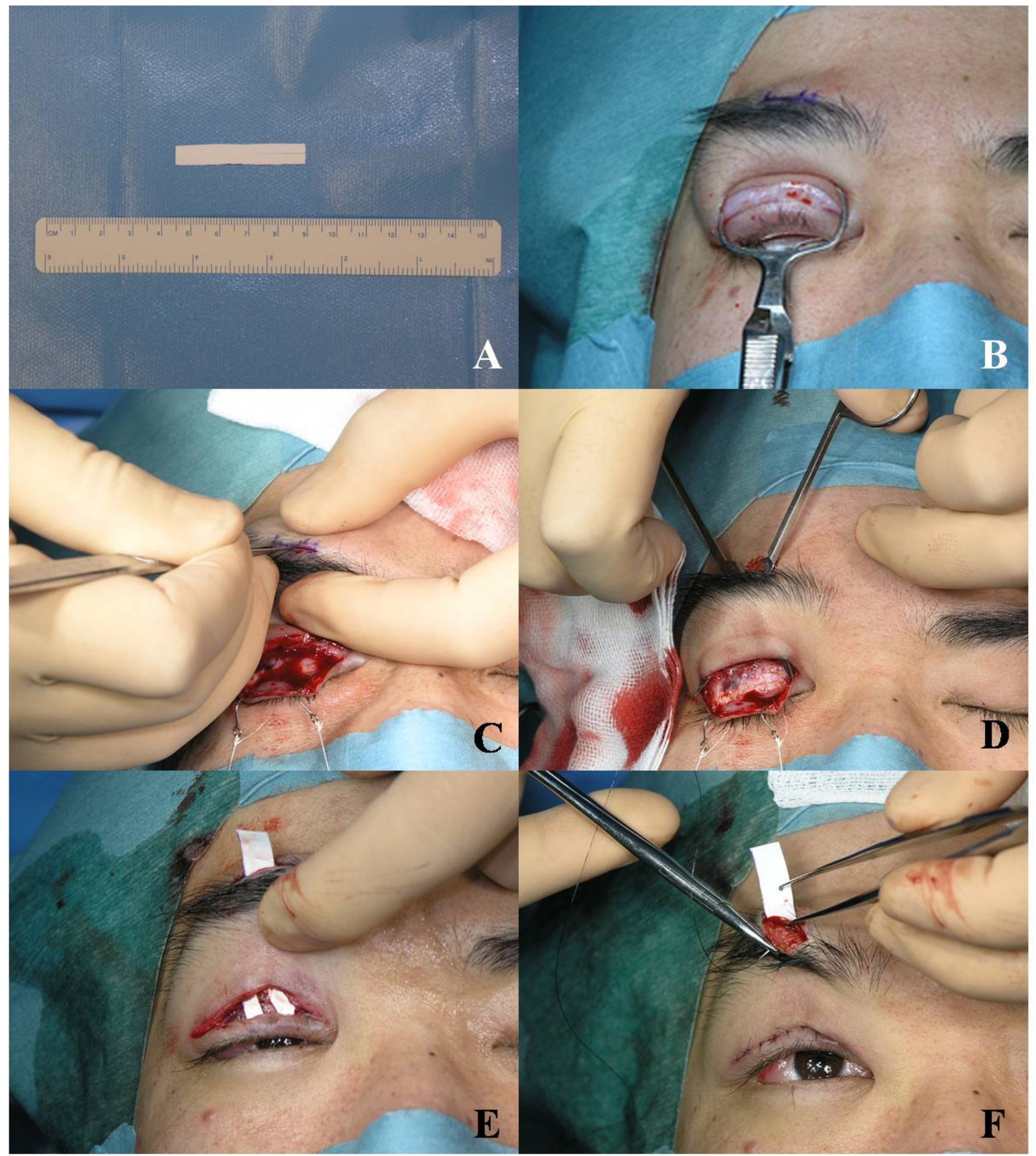

Fig. (2). Frontalis suspension surgery using a polytetrafluoroehylene (Gore-Tex ${ }^{\circledR}$ ) sheet. (A) The polytetrafluoroethylene sheet is cut (size: $45 \times 7 \mathrm{~mm}$ ) and divided into 2 branches; each is $17 \mathrm{~mm}$ in length. (B) After performing a full-width skin incision in the eyelid crease, the eyelid is clamped. (C) An eyebrow incision is made just above the pupil. (D) A preseptal tunnel is created. (E) The two branches of the sheet are fixated to the tarsus, and it is then passed through the preseptal tunnel. (F) The sheet is then fixated in the subcutaneous fibroadipose tissue under the eyebrow.

premature absorption occasionally occurs before the permanent bond formation [4], resulting in recurrence [39]. Histological findings have showed that the morphology of the banked fascia lata is almost unchanged shortly after the implantation [25], while, in the recurrent cases, the fascia disappeared [4]. Although the success rate of the sling surgery with the banked fascia lata was high in short followup period (approximately 90\%) [4, 38, 39, 41, 42], the long- 
Table 3. Comparison of Suspensory Materials in Frontalis Suspension Operations

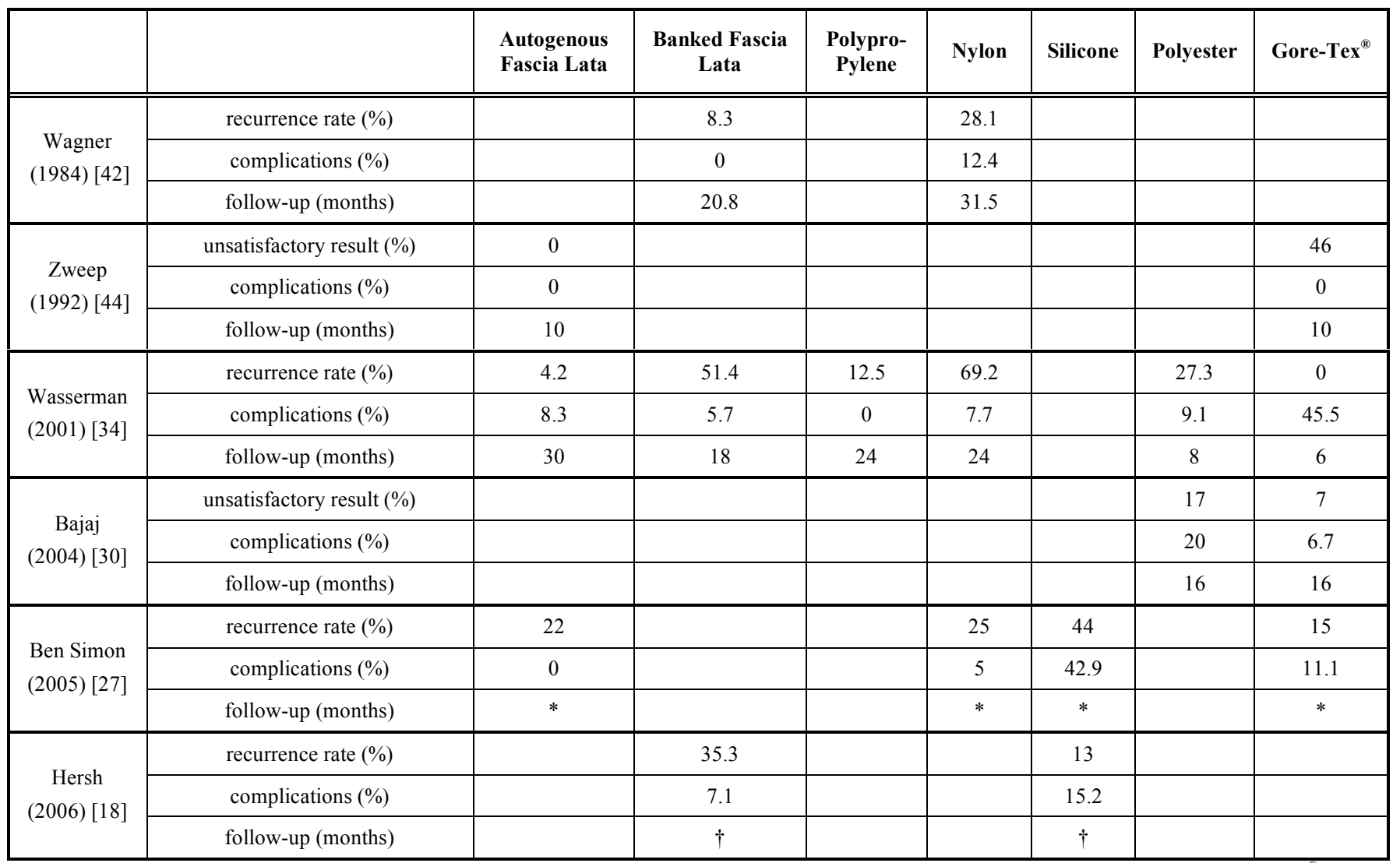

*: Although the overall mean follow-up period was 20 months, patients with silicone or autogenous fascia lata had longer follow-up periods than patients with Gore-Tex ${ }^{\beta}$ or nylon sutures.

$\dagger$ : The overall mean follow-up period was 46 months.

term success rate decreases to approximately $50 \%[18,34$, 43]. The fibrous tissue formation distresses the surgical revision [18]. A cross-infectious disease is another possible serious problem of this material [41].

\section{Synthetic Graft Materials}

Synthetic materials are more readily available and are not associated with complications such as donor-site morbidity or cross-infections. However, the recurrence rate of ptosis after frontalis suspension using alloplastic materials is generally higher than that with autogenous fascia lata [27, 34, 44] (Table 3). In addition, synthetic materials have a higher risk of extrusion, infection, granuloma formation and breakage after trauma (Fig. 3A, B).

\section{Polypropylene Suture}

A monofilament polypropylene suture $\left(\right.$ Prolene $^{\circledR}$ ) is sometimes used for frontalis suspension surgery [45]. However, since the postoperative ptosis recurrence rate is high $(12.5-55.6 \%)[34,45]$, polypropylene suture are mainly used as a temporary suspension material to prevent amblyopia in young children who are planned to undergo surgery with autogenous fascia lata when they are older [45]. The main advantages of the polypropylene suture are the low risk of scarring and soft tissue complications, easy removal, and not interfering with future use of autogenous fascia lata $[34,45]$. This suture, however, can sometimes break, produce visible suture tension lines and cause deformity of the eyelid margin [46]. The monofilament nature of this suture material impedes tissue integration, thereby causing slippage and ptosis recurrence.

\section{Nylon Suture}

Monofilament (Supramid ${ }^{\circledR}$ ) and polyfilament (Supramid Extra $^{(B}$ ) nylon sutures are also used for temporary suspension [17]. These materials have the same advantages as the polypropylene suture, as well as the high recurrence rate of ptosis (25-69.2\%) (Table 3) [27, 34, 42, 47]. The mean period to recurrence is 3 months (cases of acute drop) and 20 months (cases with gradual changes) [42].

\section{Silicone}

Silicone has become a popular material in frontalis suspension surgery [28]. Tillett and Tillett first described the use of silicone bands in frontalis suspension [48]. The band was then replaced by the less bulky silicone rods $[26,31,49$, 50]. The silicone rod is easily available and adjustable because it is encased in fibrous connective tissue and slides through it $[18,28,31]$. The most valuable advantage of the silicone rod is its elasticity, which allows complete eyelid closure and appropriate upper eyelid height [28, 31]. The silicone rod may, therefore, be best appropriate for patients with poor Bell's phenomenon [28]. Older and Dunne also showed that a silicone rod sling reduces the use of artificial tears and lubricating ointments in CPEO patients [51]. However, this material does not integrate with the fibrovascular tissue, and may therefore slip [29], resulting in 


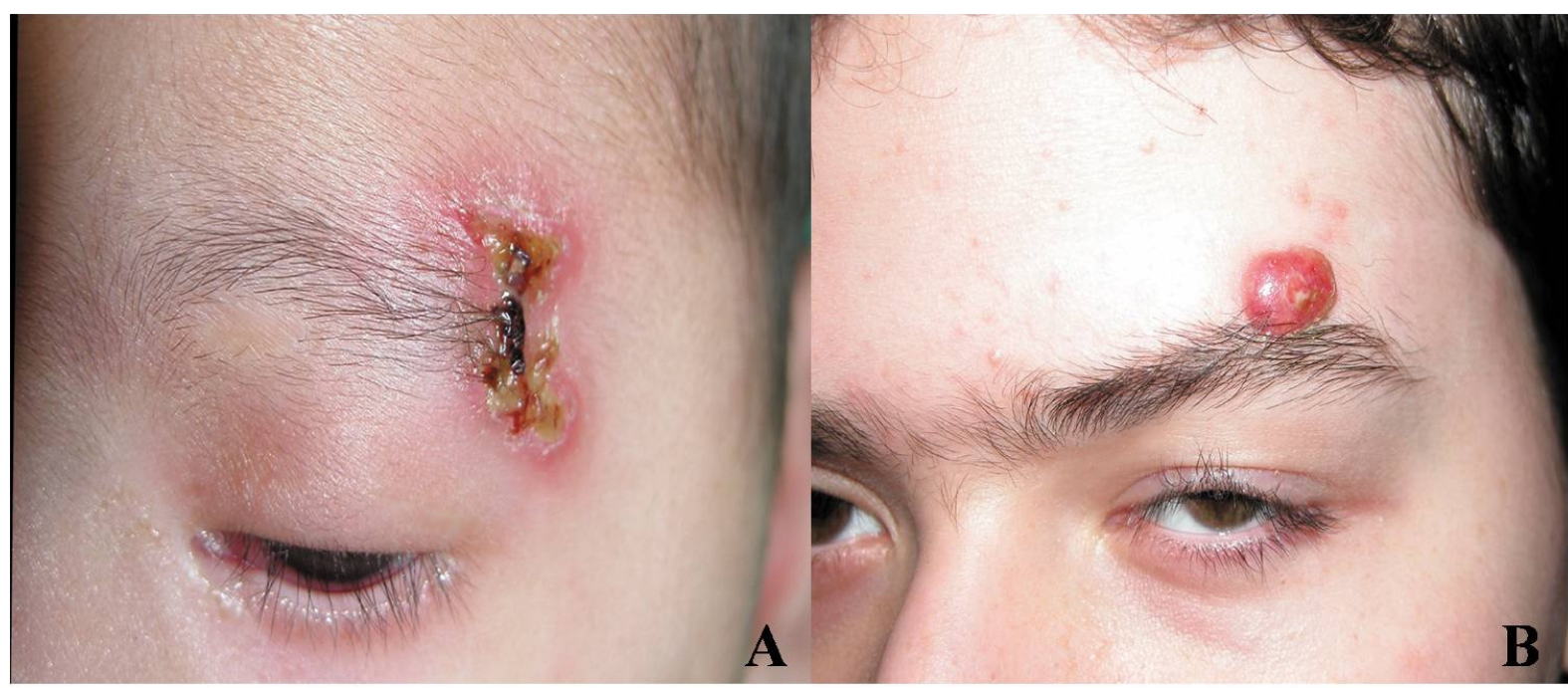

Fig. (3). Complications after silicone rod sling. (A) Infection. (B) Granuloma formation.

recurrence of ptosis [28]. The reported recurrence rate with the silicone rod sling is up to $50 \%[18,26,28,31,49]$.

\section{Mersilene $^{\circledR}$ Mesh}

Mersilene $\left.^{(}\right)$mesh is made of a polyester fiber, manufactured by a machine knotting process [29, 52, 53]. The mesh acts as a permanent scaffold, supporting fibrovascular ingrowth [29, 52-54], thereby reducing the risk of slippage and providing a long-lasting upper eyelid lift [29]. Although there are only small case series and no comparative studies, the reported recurrence rate is relatively low $(0-12.5 \%)$. This material, however, may sometimes cause soft tissue complications such as extrusion, infection and granuloma formation [54, 55], and it may be quite difficult to remove it once integrated into the fibrovascular tissues [55].

\section{Gore-Tex $^{\circledR}$}

Gore-Tex $^{\circledR}$ is a synthetic microporous polymer, comprised of nodules interconnected by multidirectional minute fibers [44]. The Gore-Tex ${ }^{\circledR}$ is one of the most biologically and chemically inert materials [30, 44]. Surgeons use Gore-Tex ${ }^{\circledR}$ sheets of $0.3 \mathrm{~mm}, 0.7 \mathrm{~mm}$, and 1.0 $\mathrm{mm}$ thick. A $0.3 \mathrm{~mm}$ sheet (Fig. 2A) is usually suitable for suspension surgery because it is less bulky and less stretchable [7]. Two comparative studies have shown that Gore-Tex $^{\circledR}$ is the most effective material for frontalis suspension surgery (recurrence rate: $0-15 \%$ ) (Table 3) [28, 34]. However, its porous nature may allow proliferation of bacterial contaminants and cause abscess formation, resulting in a high risk of soft tissue complications [34]. The micropores are too small to allow infiltration of fibrovascular tissues [44], thereby it can easily be removed or manipulated to adjust the eyelid height $[44,52]$. The fibrovascular tissue is strong enough to maintain a sufficient upper eyelid height even after removal of the material [56].

\section{CONCLUSION}

We presented an updated review on frontalis suspension surgery. Although autogenous fascia lata is still considered the material of choice for congenital ptosis repair, other sling materials can be also safely used. Familiarity with the advantages and disadvantages of each of these materials, as well as meticulous patient selection is the key to achieving a successful outcome with a low rate of complications.

\section{CONFLICT OF INTEREST}

The authors have no financial support and no financial interest related to this manuscript.

\section{REFERENCES}

[1] Dransart HN. Un cas de blépharoptose opéré par un procédé spécial à l'auteur. Guérison. Analectes Ophtalmologiques 1880; 84: 88 (German).

[2] Payr E. Plastik mittels freier Faszientransplantation bei Ptosis. Dtsch Med Wochenschr 1909; 35: 822 (German).

[3] Wright WW. The use of living sutures in the treatment of ptosis. Arch Ophthalmol 1922; 51: 99-102.

[4] Crawford JS. Repair of ptosis using frontalis muscles and fascia lata: a 20-year review. Ophthalmic Surg 1977; 8: 31-40.

[5] Crawford JS. Repair of ptosis using frontalis muscle and fascia lata. Trans Am Acad Ophthalmol Otolaryngol 1956; 60: 672-8.

[6] Anderson RL, Dixon RL. Aponeurotic ptosis surgery. Arch Ophthalmol 1979; 97: 1123-8.

[7] Kakizaki H. Gankeiseigeka Tora No Maki, Tokyo: Medical Aoi 2009; pp. 9-32 (Japanese).

[8] Finsterer J. Ptosis: causes, presentation, and management. Aesth Plast Surg 2003; 27: 193-204.

[9] Wong VA, Beckingsale PS, Oley CA, Sullivan TJ. Management of myogenic ptosis. Ophthalmology 2002; 109: 1023-31.

[10] Putterman AM, Dresner SC, Meyer DR, Wobig JL, Dailey RA. Surgery for the upper eyelid and the brow. In: Wobig JL, Dailey RA, Eds. Oculofacial Plaastic Surgery. New York: Thieme 2004; pp. 54-82.

[11] Custer PL. Ptosis: levator muscle surgery and frontalis suspension. In: Chen WP, Ed. Oculoplastic Surgery: The Essentials. New York: Thieme 2001; pp. 89-100.

[12] Ahmadi AJ, Sires BS. Ptosis in infants and children. Int Ophthalmol Clin 2002; 42: 15-29.

[13] Gusek-Schneider GC, Martus P. Stimulus deprivation amblyopia in human congenital ptosis: a study of 100 patients. Strabismus 2000; 8: 261-70.

[14] Merriam WW, Ellis FD, Helveston EM. Congenital blepharoptosis, anisometropia, and amblyopia. Am J Ophthalmol 1980; 89: 401-7.

[15] Anderson RL, Baumgartner SA. Amblyopia in ptosis. Arch Ophthalmol 1980; 98: 1068-9.

[16] Repka MX. Management of refractive error. In: Nelson LB, Calhoun JH, Harley RD, Eds. Pediatric Ophthalmology. $3^{\text {rd }}$ ed, Philadelphia: WB Saunders 1991; pp. 102-3.

[17] Saunders RA, Grice CM. Early correction of severe congenital ptosis. J Pediatr Ophthalmol Strabismus 1991; 28: 271-3. 
[18] Hersh D, Martin FJ, Rowe N. Comparison of silastic and banked fascia lata in pediatric frontalis suspension. J Pediatr Ophthalmol Strabismus 2006; 43: 212-8.

[19] Friedenwald JS, Guyton JS. A simple ptosis operation: utilization of the frontalis by means of a single rhomboid-shaped suture. Am J Ophthalmol 1948; 31: 411-4.

[20] Iliff NT. Frontalis sling. In: Rice TA, Michels RG, Stark WJ, Eds. Rob \& Smith's Operative Surgery - Ophthalmic Surgery $4^{\text {th }}$ ed. London: Butterworth 1984; pp. 35-7.

[21] Fox SA. Congenital ptosis: II frontal sling. J Pediatr Ophthalmol 1966; 3: 25-8

[22] Fan J. Frontalis suspension technique with a temporal-fasciaecomplex sheet for repairing blepharoptosis. Aneth Plast Surg 2001; 25: $147-51$.

[23] Kurihara K, Kojima T, Marumo E. Frontalis suspnsion for blepharoptosis using palmaris longus tendon. Ann Plast Surg 1984; 13: 274-8.

[24] Yoon JS, Lee SY. Long-term functional and cosmetic outcomes after frontalis suspension using autogenos fasia lata for pediatric congenital ptosis. Ophthalmology 2009; 116: 1405-14.

[25] Beyer CK, Albert DM. The use and fate of fascia lata and sclera in ophthalmic plastic and reconstructive surgery: The 1980 Wendell Hughes Lecture. Ophthalmology 1981; 88: 869-86.

[26] Goldberger S, Conn H, Lemor M. Double rhomboid silicone rod frontalis suspension. Ophthal Plast Reconstr Surg 1991; 7: 48-53.

[27] Ben Simon GJ, Macedo AA, Schwarcz RM, et al. Frontalis suspension for upper eyelid ptosis: evaluation of different surgical designs and suture material. Am J Ophthalmol 2005; 140: 877-85.

[28] Carter SR, Meecham WJ, Seiff SR. Silicone frontalis slings for the correction of blepharoptosis: indications and efficacy. Ophthalmology 1996; 103: 623-30.

[29] Kemp EG, MacAndie K. Mersilene mesh as an alternative to autogenous fascia lata in brow suspension. Ophthal Plast Reconstr Surg 2001; 17: 419-22.

[30] Bajaj MS, Sastry SS, Ghose S, Betharia SM, Pushler N. Evaluation of polytetrafluoroethylene suture for frontalis suspension as compared to polybutylate-coated braided polyester. Clin Exp Ophthalmol 2004; 32: 415-9.

[31] Leone CR Jr, Shore JW, Van Germert JV. Silicone rod frontalis sling for the correction of blepharoptosis. Ophthalmic Surg 1981; 12: 881-7.

[32] Spoor TC, Kwitko GM. Blepharoptosis repair by fascia lata suspension with direct tarsal and frontalis fixation. Am J Ophthalmol 1990; 109: 314-7.

[33] Kakizaki H, Zako M, Nakano T, et al. The levator aponeurosis consists of two layers that include smooth muscle. Ophthal Plast Reconstr Surg 2005; 21: 281-4.

[34] Wasserman BN, Sprunger DT, Helveston EM. Comparison of materials used in frontalis suspension. Arch Ophthalmol 2001; 119: 687-91.

[35] Leibovitch I, Leibovitch L, Dray JP. Long-term results of frontalis suspension using autogenous fascia lata for congenital ptosis in children under 3 years of age. Am J Ophthalmol 2003; 136: 86671.

[36] Orlando F, Weiss JS, Bayer-Machule CK, Albert DM, Shapiro A. Histopathologic condition of fascia lata implant 42 years after ptosis repair. Arch Ophthalmol 1985; 103: 1518-9.
[37] Crawford JS. Fascia lata: its nature and fate after implantation and its use in ophthalmic surgery. Trans Am Ophthalmol Soc 1968; 66: 673-745.

[38] Crawford JS. Recent trends in ptosis surgery. Ann Ophthalmol 1975; 7: 1263-7.

[39] Crawford JS. Frontalis sling operation. J Pediatr Ophthalmol Strabismus 1982; 19: 253-5.

[40] Townsend AL, Crawford JS. Stored fascia lata for ophthalmic surgery. Can J Ophthalmol 1969; 4: 331-8.

[41] Broughton WL, Matthews II JG, Harris DJ Jr. Congenital ptosis: results of treatment using lyophilized fascia lata for frontalis suspensions. Ophthalmology 1982; 89: 1261-6.

[42] Wagner RS, Mauriello JA Jr, Nelson LB, et al. Treatment of congenital ptosis with frontalis suspension: a comparison of suspensory materials. Ophthalmology 1984; 91: 245-8.

[43] Wilson ME, Johnson RW. Congenital ptosis: long-term results of treatment using lyophilized fascia lata for frontalis suspensions. Ophthalmology 1991; 98: 1234-7.

[44] Zweep HP, Spauwen PHM. Evaluation of expanded polytetrafluoroethylene (e-PTFE) and autogenous fascia lata in frontalis suspnesion. Acta Chir Plast 1992; 34: 129-37.

[45] Manners RM, Tyers AG, Morris RJ. The use of prolene as a temporary suspension material for brow suspension in young children. Eye 1994; 8: 346-8.

[46] Hildreth HR, Silver B. Physiologic approach to frontalis lid suspension. Trans Am Acad Ophthalmol Otolaryngol 1970; 74: 427-8.

[47] Katowitz JA. Frontalis suspension in congenital ptosis using a polyfilament, cable-type suture. Arch Ophthalmol 1979; 97: 165963.

[48] Tillett CW, Tillett GM. Silicone sling in the correction of ptosis Am J Ophthalmol 1966; 62: 521-3.

[49] Rowan PJ, Hayes GS. Silicone sling for ptosis. South Med J 1977; 70: 68-9.

[50] Leone CR Jr, Rylander G. A modified silicone frontalis sling for the correction of blepharoptosis. Am J Ophthalmol 1978; 85: 8025 .

[51] Older JJ, Dunne PB. Silicone slings for the correction of ptosis associated with progressive external ophthalmoplegia. Ophthalmic Surg 1984; 15: 379-81.

[52] Downes RN, Collin JRO. The Mersilene mesh sling - a new concept in ptosis surgery. Br J Ophthalmol 1989; 73: 498-501.

[53] Lam DSC, Gandhi SR, Ng JSK, et al. Early correction of severe unilateral infant ptosis with the Mersilene mesh sling. Eye 1997; 11: 806-9.

[54] Mehta P, Patel P, Olver JM. Functional results and complications of Mersilene mesh use for frontalis suspension ptosis surgery. $\mathrm{Br} \mathrm{J}$ Ophthalmol 2004; 88: 361-4.

[55] Mehta P, Patel P, Olver JM. Management of Mersilene mesh chronic eyelid complications: a systematic approach. Eye 2004; 18 : 640-2.

[56] Steinkogler FJ, Kuchar A, Huber E, Arocker-Mettinger E. GoreTex soft-tissue patch frontalis suspension technique in congenital ptosis and in blepharophimosis-ptosis syndrome. Plast Reconstr Surg 1993; 92: 1057-60. 